\title{
Analisis Dinamika Stroller (Kereta Bayi) dengan Metode Port- Controlled Hamiltonian System (PCHS) berbasis Komputasi Fisika
}

\author{
Melly Ariska ${ }^{1 \star}$, Hamdi Akhsan², dan Muhammad Muslim ${ }^{3}$ \\ 1,2,3 Pendidikan Fisika FKIP Universitas Sriwijaya \\ Jalan Raya Palembang-Prabumulih KM 32 Indralaya Ogan Ilir \\ *E-mail: mellyariska@fkip.unsri.ac.id
}

\begin{abstract}
Abstrak
Komputasi fisika dapat digunakan dalam membantu menyelesaikan persamaan dinamika benda yang kompleks, baik translasi maupun rotasi. Tujuan penelitian ini adalah mendapatkan perbedaan dinamika sistem mekanik dengan kendala tak holonomik pada berbagai ruang konfigurasi. Reduksi yang digunakan adalah perhitungan matematis persamaan Port-Contolled Hamiltonian System (PCHS) pada sistem mekanik yaitu Stroller (kereta bayi), sehingga persamaan yang digunakan dalam menentukan persamaan gerak Stroller dengan dan tanpa gesekan yang bergerak di bidang melengkung berupa permukaan bola pepat dengan syarat awal yang bervariasi. Metode ini dapat menurunkan persamaan gerak Stroller yang bergerak di bola pepat. Hasil temuan penelitian ini adalah persamaan dinamika dan grafik persamaan Stroller dengan dan tanpa gesekan yang bergerak di bidang melengkung berupa bola pepat dengan syarat awal yang bervariasi berbasis maple. Penelitian ini membuktikan konsep-konsep fisika mengenai dinamika dan kinematika serta menganalisis dinamika Stroller menggunakan komputasi fisika untuk mengetahui karakteristik gerakan Stroller yang kompleks dan rumit, baik secara translasi maupun rotasi.
\end{abstract}

Kata kunci: Dinamika, Stroller, Metode PCHS, Komputasi Fisika

\begin{abstract}
Computational physics can be used to help solve complex dynamics equations, both translational and rotational. The purpose of this study is to obtain differences in the dynamics of mechanical systems with non-holonomic constraints in various flat and curved configuration spaces based on physics computing. In this study the reduction used is a mathematical calculation of the Port-Contolled Hamiltonian System (PCHS) equation in a mechanical system that is a Stroller, so that the equation used in determining the Stroller motion equation with and without friction that moves in the curved plane in the form of a spherical surface with various initial conditions based on maple is Poincaré's equation which is based on Routhian reduction with and without friction. The effect of friction can be clearly seen through dynamics and graphical equations on the Stroller. This method can reduce the Stroller motion equation with and without friction that moves on the ball sphere clearly in the form of a set of differential equations. The findings of this study are dynamic equations and graphs of Stroller equations with and without friction that move in the curved plane in the form of a spherical ball with varying initial conditions based on maples. This study proves physical concepts about dynamics and kinematics and analyzes Stroller dynamics using computational physics to determine the characteristics of complex and complex Stroller movements, both translational and rotational.
\end{abstract}

Keywords: Dynamics, Stroller, PCHS Method, Computational Physics

\section{PENDAHULUAN}

Mekanik geometrik merupakan bidang kajian fisika matematika, teknik, dan matematika yang subur dengan tema penelitian (Fowles \& Cassiday, 2004). Banyak gagasan dan perkembangan mekanika geometrik yang telah berperan dalam disiplin ilmu lain untuk menangani masalah-masalah yang bersifat praktis (M. Ariska et al., 2019). Terapan mekanika geometrik dapat ditemukan diberbagai bidang seperti robotika, dinamika kendaraan, dan gerak lokomotif pada berbagai gerak hewan yang melibatkan mekanika tak holonomik (M. Ariska et al., 2020b).

Sepanjang sejarah, telah banyak ilmuwan yang datang dari berbagai disiplin 
ilmu untuk mempelajari sistem mekanika tak holonomik (Ciocci et al., 2012). Sistem tak holonomik diperkenalkan dalam mekanika oleh Hertz pada tahun 1894, yang berarti bahwa sistem yang mengalami kendala-kendala yang membatasi kecepatan partikel sistem dalam ruang konfigurasi (Glad et al., 2007). Kendala adalah keadaan yang membatasi gerak sistem mekanik sehingga mengurangi baik derajat kebebasan maupun range tiap derajat kebebasan. Kendala tak holonomik selalu melibatkan kecepatan sistem dan dapat dituliskan dalam forma berderajat satu (Melly Ariska et al., 2018). Kendala ini ditemukan ditemukan dalam ruang konfigurasi dan tidak mengurangi derajat kebebasan serta membatasi gerakan sistem dalam ruang konfigurasi dan momentum (M. Ariska et al., 2020). Sistem dapat digambarkan dengan keragaman (manifold), yaitu suatu upaya membangun tata koordinat dari suatu ruang berupa kumpulan titik-titik, garis-garis atau fungsi-fungsi (Melly Ariska et al., 2020a; Branicki et al., 2006). Ruang konfigurasi yang digunakan berupa grup Lie, maka untuk mencari kendala teori grup dapat dikaryakan, akan tetapi dalam penelitian ini kita cukup menggunakan perhitungan diferensial (Branicki \& Shimomura, 2006).

Stroller merupakan contoh sederhana sistem gerak lokomotif dengan kendala tak holonomik, namun kajian mekanikanya tidak sepele. Stroller sering dihubungkan dengan kendaraan roda tiga kecil yang digunakan oleh anak-anak balita. Kita akan melakukan pendekatan pemodelan dari sudut pandang sistem Hamiltonian terkendali (Port Controlled Hamiltonian System), karena Port Controlled Hamiltonian System (PCHS) merupakan salah satu cara untuk menyatakan energi sistem dengan tegas (Naomi Altman \& Martin Krzywinski, 2015). Selain itu Port Controlled Hamiltonian System adalah sistem dinamika yang dapat digambarkan denga himpunan persamaan diferensial. Dalam penelitian ini, persamaan gerak Stroller akan diturunkan melalui dua metode, yaitu PCHS dan Koneksi Levi-Civita terkendala (Shaidullin et al., 2014).

Sistem dengan kendala tak holonomik dapat disembunyikan dengan membangun atau memilih koneksi Levi-Civita tertentu. Tujuan disembunyikannya kendala adalah untuk menghilangkan pengali Lagrange pada persamaan gerak. Penelitian ini merupakan upaya untuk lebih memahami sitem dengan kendala tak holonomik dari sudut pandang mekanika geometrik, yang akan menganalisis masalah gerak secara geometris (Melly Ariska et al., 2020b).

Komputer dalam Pembelajaran Fisika merupakan mata kuliah yang perlu dikembangkan secara global. Hal ini dilakukan untuk mempersiapkan generasi yang maju dan sadar akan pentingnya teknologi dalam menghadapi revolusi industri 4.0 (Akhsan et al., 2020). Fisika merupakan cabang ilmu yang berkembang pesat mengikuti perkembangan teknologi yang ada. Peserta didik harus dipersiapkan dengan baik dalam menghadapi perkembangan teknologi. Teknologi dalam pembelajaran fisika dapat ditanamkan dalam proses pembelajaran di kelas. Contohnya dalam mata kuliah komputer dalam pembelajaran fisika.

Gerak benda yang akan dibahas dalam penelitian ini adalah gerak Stroller. Mengingat gerak Stroller merupakan contoh gerak benda yang dapat bergerak secara translasi maupun rotasi (Blankenstein, 2003). Pada penelitian pada penelitian yang dilakukan (M. Ariska et al., 2020b) telah berhasil menyelesaikan persamaan dinamika gasing balik di bidang datar sekaligus menggambarkan persamaan geraknya dengan menggunakan komputasi fisika. Pada penelitian ini peneliti akan menganalisis sistem dinamik yang rumit dan kompleks lainnya yag bergerak di bidang datar dan bola pepat sekaligus dengan dan tanpa gesekan (Bou-Rabee et al., 2004; Ciocci et al., 2012). Penelitian akan memprediksi dinamika Stroller di permukaan dalam bola pepat dengan bantuan komputasi fisika. Dalam menyelesaikan persamaan ini bukanlah hal yang mudah, karena ruang konfigurasi yang akan dilewati Stroller merupakan bola pepat yang merupakan bidang lengkung yang memiliki variabel koordinat elips dan koordinat Stroller yang bergerak dengan menggunakan tiga sistem koordinat, sehingga jumlah koordinat umum yang akan diselesaikan 
adalah enam koordinat umum, yaitu satu koordinat translasi dan lima koordinat rotasi. Selain itu peneliti juga akan menganalisis sekaligus memprediksi gerakan Stroller dengan dan tanpa gesekan.

Masalah yang diselesaikan dalam penelitian ini adalah bagaimana menganalisis gerak Stroller pada ruang konfigurasi translasi berbasis komputasi fisika. Penelitian ini akan menerapkan teknologi dalam menyelesaikan persamaan umum suatu sistem gerak pada ruang tiga dimensi. Mengingat semakin berkembangnya ilmu pengetahuan dan teknologi di dunia pendidikan, dinamika benda yang memiliki ruang konfigurasi yang cukup rumit karena terdiri dari gerak translasi dan rotasi yang sangat rumit jika diselesaikan secara manual. Penelitian ini menjadi solusi bagi dosen dan mahasiswa dalam menyelesaikan dinamika benda yang kompleks secara menyeluruh dan presisi. Penelitian ini bertujuan menganalisis dinamika sistem mekanik pada Stroller dengan kendala tak holonomik yang bergerak pada ruang konfigurasi translasi dengan menggunakan komputasi fisika.

Persamaan gerak tipe top dengan menerapkan teori grup berupa grup rotasi dengan menggunakan persamaan Poincare di bidang datar telah dirumuskan oleh Ariska (2019) dengan komputasi fisika. Selain itu, penelitian sebelumnya dinamika sistem mekanik hanya dirumuskan untuk tippe top yang bergerak di bidang datar dan permukaan dalam silinder. Oleh sebab itu, penulis tertarik untuk melanjutkan penelitian dengan merumuskan dinamika sistem yang memiliki gerakan lebih kompleks yaitu Stroller yang dimainkan di bidang melengkung berupa permukaan dalam bola pepat dengan dan tanpa gesekan. Prediksi gerakan secara rinci akan dianalisis menggunakan komputasi fisika.

\section{METODE/EKSPERIMEN}

Penelitian ini bersifat kajian teoretis matematis yang dilakukan dengan tinjauan terhadap beberapa pustaka mengenai sistem mekanik pada kasus Stroller yang telah dikembangkan sebelumnya serta perhitungan matematis dengan menggunakan komputasi fisika, khususnya berbasis Maple. Penelitian ini tersusun dari empat tahap dengan uraian singkat sebagai berikut ini:

1. Pengenalan komputasi berupa Maple kepada mahasiswa pendidikan fisika melalui tutorial tentang cara penggunaan, menginstal, dan penerapannya dalam menghitung persamaan gerak benda ruang tiga dimensi.

2. Pembahasan materi tentang koordinat umum, ruang konfigurasi, gaya umum, persamaan Eular-Lagrange, Persamaan Poincaré, penyederhanaan persamaan Poincaré dengan teori grup dan Metode PCHS, koordinat siklik dan reduksi Routhian pada mahasiswa dan penerapannya dalam menganalisis gayagaya pada Stroller di permukaan dalam bola pepat dengan menggunakan Maple.

3. Pembahasan dinamika Stroller, persamaan gerak Stroller melalui persamaan EularLagrange dan mereduksi persamaan EularLagrange dengan dengan menggunakan Maple.

\section{HASIL DAN PEMBAHASAN}

\section{HASIL}

Perhitungan Kendala Stroller diselesaikan dengan metode Port-Contolled Hamiltonian System (PCHS). Kendala adalah keadaan yang membatasi gerak system mekanik sehingga mengurangi baik derajat kebebasan maupun range tiap derajat kebebasan. Skematik Dinamika Stroller dapat dilihat pada Gambar 1 di bawah ini. 


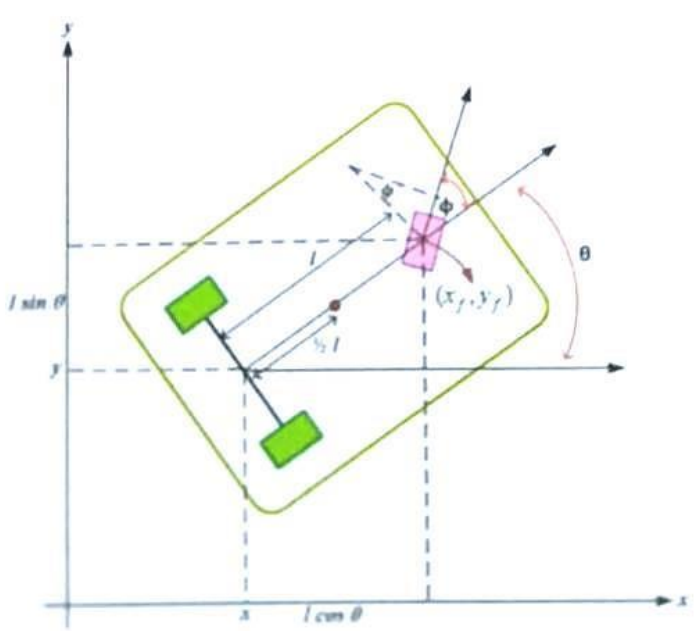

Gambar 1. Skematik Dinamika Stroller

Sudut absolut roda depan adalah $(\theta+\varphi)$. Roda depan terletak pada $\left(x_{\text {depan }}, y_{\text {depan }}\right)=$ $(x+l \cos \theta, y+l \sin \theta)$, dan turunan posisi roda depan terhadap waktu adalah $\left.\dot{x}_{\text {depan }}, \dot{y}_{\text {depan }}\right)=(\dot{x}-l \sin \theta \dot{\theta}, \dot{y}+l \cos \theta \dot{\theta})$.

Kendala saat tidak selip dapat dituliskan dengan,

$-\sin \theta \dot{x}_{\text {belakang }}+\cos (\theta+\varphi) \dot{y}_{\text {belakang }}=0$

$-\sin (\theta+\varphi) \dot{x}_{\text {depan }}+\cos (\theta+\varphi) \dot{y}_{\text {depan }}=0$

Kendala untuk Stroller yang bergerak pada bidang datar dapat ditulis dengan,

$$
\begin{aligned}
\tan \theta & =\frac{\sin \theta}{\cos \theta}=\frac{\dot{y}_{\text {belakang }}}{\dot{x}_{\text {belakang }}} \\
\omega^{1}(q) \dot{q} & =-\sin \theta \dot{x}+\cos \theta \dot{y}=0
\end{aligned}
$$

dan

$$
\begin{aligned}
& \tan (\theta+\varphi)=\frac{\sin (\theta+\varphi)}{\cos (\theta+\varphi)}=\frac{\dot{y}_{\text {depan }}}{\dot{x}_{\text {depan }}} \\
& \omega^{2}(q) \dot{q}=-(\dot{x}-l \sin \theta \dot{\theta}) \sin (\theta+\varphi) \\
& +(\dot{y}+l \cos \theta \dot{\theta}) \cos (\theta+\varphi) \\
& =0 \\
& \omega^{2}(q) \dot{q}=-\sin (\theta+\varphi) \dot{x}+\cos (\theta+\varphi) \dot{y}+ \\
& l \cos \varphi \dot{\theta}=0
\end{aligned}
$$

Andaikan titik $\mathrm{P}$ memiliki koordinat $(x, y, z)$ dalam suatu sistem koordinat kartesius, maka titik tersebut memiliki koordinat $(\xi, \eta, \mu)$, sedemikian rupa sehingga

$$
\begin{aligned}
& x=a \cosh \xi \cos \eta \cos \mu \\
& y=a \cosh \xi \cos \eta \sin \mu
\end{aligned}
$$

$$
z=a \sinh \xi \sin \mu
$$

dengan menggunakan diferensial eksak,

$$
\begin{aligned}
& d x= \frac{\partial x}{\partial \xi} d \xi+\frac{\partial x}{\partial \eta} d \eta+\frac{\partial x}{\partial \mu} d \mu \\
&=-a \cosh \xi \sin \eta \cos \mu d \eta \\
&-a \cosh \xi \cos \eta \sin \mu d \mu \\
& d y=\frac{\partial y}{\partial \xi} d \xi+\frac{\partial y}{\partial \eta} d \eta+\frac{\partial y}{\partial \mu} d \mu \\
&=-a \cosh \xi \sin \eta \sin \mu d \eta \\
&+a \cosh \xi \cos \eta \cos \boldsymbol{\mu} \boldsymbol{d} \boldsymbol{\mu}
\end{aligned}
$$

Persamaan (5) disubstitusikan ke persamaan (2) dan (3), maka dengan trans-formasi koordinat kartesius ke koordinat kartesian ke koordinat bola pepat, diperoleh kendala stroller yang bergerak pada permukaan salam bola pepat yang dapat dituliskan dengan,

$$
\begin{aligned}
& \omega^{1}=-\sin \theta d x+\cos \theta d y \\
& =a \cosh \xi \sin \eta \sin (\theta-\mu) d \eta \\
& \begin{array}{r}
\omega^{2}=-\sin (\theta+\varphi) d x+\cos (\theta+\varphi) d y \\
\quad+l \cos \varphi d \theta \\
=a \cosh \xi \sin \eta \sin (\theta+\varphi-\mu) d \eta+ \\
a \cosh \xi \cos \eta \cos (\theta+\varphi-\mu) d \mu+ \\
\quad l \cos \varphi d \theta
\end{array}
\end{aligned}
$$

Perhitungan Matematis Persamaan PortControlled Hamiltonian System Pada Stroller (PCHS) terkendala pada Stroller yang bergerak pada permukaan dalam bola pepat memiliki koordinat umum $\dot{q}^{i}=\left[\begin{array}{llll}\dot{\eta} & \dot{\mu} & \dot{\theta} & \dot{\varphi}\end{array}\right]$, dan koordinat momentum $\dot{p}_{i}=\left[\begin{array}{llll}\dot{p}_{\eta} & \dot{p}_{\mu} & \dot{p}_{\theta} & \dot{p}_{\varphi}\end{array}\right]$, maka dapat dituliskan dengan,

$$
\begin{array}{r}
H(q, p)=\left[\frac{p_{\eta}^{2}}{2 m a \sqrt{\sinh ^{2} \xi+\sin ^{2} \eta}}+\frac{p_{\mu}^{2}}{2 m a \cosh \xi \cosh \eta}+\right. \\
m g a \sinh \xi(1+\sin \eta)]
\end{array}
$$

Sedangkan persamaan kendala Stroller dapat dituliskan dalam bentuk matriks dengan,

$$
\left[\begin{array}{l}
0 \\
0
\end{array}\right]=\left[\begin{array}{c}
\frac{\cosh \xi}{m}\left(\frac{p_{\eta} \sin \eta \sin (\theta-\mu)}{\sqrt{\sinh ^{2} \xi}+\sin ^{2} \eta}\right) \\
\frac{\cosh \xi}{m}+p_{\theta} l \cos \varphi
\end{array}\right]
$$

Apabila sebuah elips diputar pada sumbu 
pendeknya, maka permukaan yang disapu oleh elips itu berupa bangun dua dimensi yang disebut bola pepat (oblate spheroida). Sistem koordinat ini dinamakan sistem koordinat bola pepat yang berhubung salah satu koordinatnya $(\xi=$ konstanta) berbentuk bola pepat. Dalam sistem koordinat ini setiap titik dalam tuang ditandai oleh tiga bilangan $(\xi, \eta, \varphi)$ dengan $0 \leq \xi \leq \infty, 0 \leq \eta \leq \pi$ dan $0 \leq$ $\mu \leq 2 \pi$. Suatu titik $P$ yang memiliki koordinat $(x, y, z)$ dalam suatu koordinat kartesius, memiliki koordinat $(\xi, \eta, \varphi)$,sedemikian rupa sehingga,

$$
\begin{aligned}
x & =a \cosh \xi \cos \eta \cos \mu \\
y & =a \cosh \xi \cos \eta \sin \mu \\
z & =a \sinh \xi \sin \mu
\end{aligned}
$$

Dengan a suatu bilangan riil positif. Bola pepat ditampilkan dalam bentuk luasan orthogonal, yaitu berupa Sferoida pepat dan Hiperboloida berdaun tunggal dan bidang datar melalui sumbu $z$ dengan $\mu=$ konstan. Faktor skala dalam bola pepat bernilai,

$$
\begin{aligned}
h_{\xi}=h_{\eta} & =a \sqrt{\sinh ^{2} \xi+\sin ^{2} \eta} \\
h_{\mu} & =a \cosh \xi \cos \eta
\end{aligned}
$$

\section{PEMBAHASAN}

Asal usul studi tentang sistem tak holonomik dijelaskan oleh Cohen dalam bukunya pada tahun 1977, bahwa kelahiran teori dinamika sistem tak holonomik terjadi pada saat diperolehnya fomalisme analitis umum yang termasuk dalam persamaan Euler-Lagrange, yang kemudian menarik banyak perhatian ilmuwan kemukakan (BouRabee et al., 2008). Ada banyak masalah yang merupakan sistem mekanik tak holonomik seperti robotika, dinamika kendaraan, gerak terus-menerus, dan sistem terkendala.

Dalam tiga puluh tahun terakhir, konsep dan penggunaan robot telah berkembang, baik untuk industri, kesehatan, riset maupun dalam kerumahtanggaan. Kata robot diperkenalkan pada tahun 1921 oleh Capek dalam Rossum's Universal Robots (R. $\mathrm{U}$. R) dengan menggambarkan mesin robot yang menyerupai orang, akan tetapi dapat bekerja tanpa lelah. Hal ini membuat (Ciocci et al., 2012; Ciocci \& Langerock, 2007; Zobova, 2012) mengembangkan dasar matematika untuk memahami manipulasi robot yang berperilaku tak holonomik dengan perumusan kinematika, dinamika, dan kendali manipulator robot. Ariska (2020) telah mengembangkan suatu perumusan matematika umum mempelajari sistem mekanika tak holonomik.

Snakeboard dan roller racer berkaitan erat dengan sistem robot dengan kendala tak holonomik. (Rauch-Wojciechowski et al., 2005) menganalisis model snakeboard, dan dinamika serta gaya pengendali pada snakeboard dengan menggunakan persamaan Lagrange. Sementara itu, studi tentang roller racer dibahas oleh (Gray \& Nickel, 2000). Gerak terus menerus melalui variasi siklik derajat kebebasan yang dipilih pada sistem mekanika yang tunduk pada kendala tak holonomik, yang memuat geometri, mekanika, dan gerak terkendali pada roller racer. Kemudian (Rutstam, 2010) melengkapi analisis kinematika pada roller racer dengan diamika sistem menggunakan persamaan gerak Lagrange-d'Alembert.

(Gray \& Nickel, 2000) menjelaskan bahwa sistem terkendali dengan kendala tak holonomik, gaya luar, dan simetri misalnya untuk kasus snakeboard dan roller racer dapat digambarkan dengan koneksi terkendala melalui pemilihan koneksi yang tepat, yang disebut koneksi Levi-Civita terkendala. (Melly Ariska et al., 2020a) merumuskan cara yang tepat untuk menghitung simbol Christoffel koneksi Levi-Civita terkendala, dan untuk mengetahui pengaruh gaya luar terhadap persamaan gerak. Untuk menambah wawasan dalam sistem dinamika, Ariska,dkk. (2019) mengusulkan sistem Hamiltonan terkendali (Port Contolled Hamiltonian System) yang berkaitan dengan mometum dan holoomik. Penelitian ini mencoba untuk menampilkan dinamika tricycle yang bergerak pada bidang datar dan permukaan dalam bola pepat dengan koneksi Levi-Civita terkendala, dan menemukan persamaan PCHS pada tricycle.

Penelitian tentang sistem dinamika benda non holonomik telah dibahas di 
beberapa artikel ilmiah diantaranya adalah Gray,dkk. (2010), Ueda dkk. (2005), Ariska (2020), dan Ciocci, dkk. (2008). Gray,dkk. (2010) mengemukakan perumusan teorema Evan tentang pembenaman sebagian sistem tricycle dan menjelaskan hubungan antara pembenaman dengan lubang yang berpola. Ueda, dkk. (2005) mengemukakan tentang pengoperasian optimal Tricycle dalam waktu terbatas dengan kerugian konduksi panas. Artikel tersebut bertujuan untuk menemukan batas prinsip tentang efek bersih proses operasi mesin panas dalam kendala waktu terbatas, selain itu juga untuk mengidentifikasi dan memodelkan mekanisme rugi pada saat operasi mesin panas.

Ciocci (2008) menggambarkan pengembangan model matematika untuk sistem non holonomik. Model matematika benda dibuat dengan menggunakan kerangka kerja Euler Lagrange. Model tersebut diimplantasikan dengan menggunakan fungsi C MEX pada MATLAB. (Ciocci \& Langerock, 2007; Ueda et al., 2005) meninjau sistem terkendali untuk meninjau sistem terkendali untuk seluruh robot yang bergerak dengan roda baik hardware maupun software, berdasarkan teknik terkendali elektronik.

Komputasi yang digunakan berbasis Maple 18 yang digunakan untuk memodelkan persamaan gerak Stroller dengan Metode PCHS. Medan vector untuk Stroller yang bergerak pada bidang datar dapat dituliskan dengan matriks sebagai berikut,

$$
\begin{aligned}
& X_{1}=l \cos \theta \frac{\partial}{\partial x}+l \sin \theta \frac{\partial}{\partial y}+\tan \varphi \frac{\partial}{\partial \varphi} \\
& X_{2}=\frac{\partial}{\partial \varphi}
\end{aligned}
$$

Bukti bahwa kedua medan vektor ini orthogonal adalah,

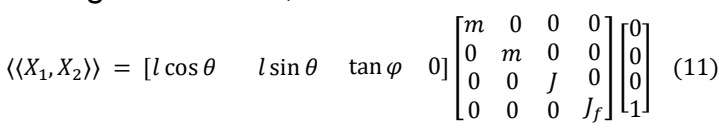

Medan Vektor untuk Stroller yang bergerak di permukaan dalam Bola Pepat adalah,

$X_{1}=l \cos \eta \cos (\theta-\mu) \frac{\partial}{\partial \eta}-l \sin \eta \sin (\theta-\mu) \frac{\partial}{\partial \mu}$

$X_{2}=\frac{\partial}{\partial \varphi}$
Bukti bahwa kedua vektor tersebut saling tegak lurus adalah,

$\left\langle\left\langle X_{1}, X_{2}\right\rangle\right\rangle=\left[\begin{array}{llll}x_{1}^{\eta} & x_{1}^{\mu} & x_{1}^{\theta} & 0\end{array}\right]\left[\begin{array}{cccc}m a \sqrt{\sinh ^{2} \xi+\sin ^{2} \eta} & 0 & 0 & 0 \\ 0 \cosh \xi+\cos \eta & 0 & 0 \\ 0 & 0 & J & 0 \\ 0 & 0 & 0 & J_{f}\end{array}\right]\left[\begin{array}{c}0 \\ 0 \\ 0 \\ x_{2}^{\varphi}\end{array}\right]$

sehingga didapatkan dengan komputasi fisika berbasis Maple 18 bahwa Persamaan PCHS terkendala untuk Stroller yang bergerak pada bidang datar dengan energi yang rendah adalah,

$$
\left[\begin{array}{c}
\dot{x} \\
\dot{y} \\
\dot{\theta} \\
\dot{\varphi} \\
\dot{p}_{x} \\
\dot{p}_{y} \\
\dot{p}_{\theta} \\
\dot{p}_{\varphi}
\end{array}\right]=\left[\begin{array}{c}
\frac{p_{x}}{m} \\
\frac{p_{y}}{m} \\
\frac{p_{\theta}}{J} \\
\frac{\dot{p}_{\varphi}}{J} \\
-\lambda_{1} \sin \theta-\lambda_{2} \sin (\theta+\varphi) \\
-\lambda_{1} \cos \theta-\lambda_{2} \cos (\theta+\varphi) \\
\lambda_{2} l \cos \varphi \\
0
\end{array}\right]
$$

dengan peubah luaran,

$$
y^{1}=\frac{p_{x}}{m}+\frac{p_{y}}{m}=\frac{1}{m}\left(p_{x}+p_{y}\right)
$$

Sementara persamaan PCHS terkendala untuk Stroller yang bergerak pada permukaan dalam bola pepat adalah,

$$
\begin{aligned}
\dot{\eta} & =\frac{p_{\eta}}{m a \sqrt{\sinh ^{2} \xi+\sin ^{2} \eta}} \\
\dot{\mu} & =\frac{p_{\mu}}{m a \cosh \xi \cos \eta} \\
\dot{\theta} & =\frac{p_{\varphi}}{J_{f}} \\
\dot{p}_{\eta} & =\frac{\sin \eta}{2 m a}\left(\frac{p_{\eta}^{2} \cos \eta}{\left(\sinh ^{2} \xi+\sin ^{2} \eta\right)^{3 / 2}}\right. \\
\dot{p}_{\mu} & =a \cosh \xi \cos \eta\left(\lambda_{1} \cos (\theta-\mu)\right. \\
& \left.\quad+\lambda_{2} \cos (\theta+\varphi-\mu)\right) \\
\dot{p}_{\theta} & =\left(\lambda_{2} l \cos \varphi\right)
\end{aligned}
$$

$$
\dot{p}_{\varphi}=0
$$

Dengan peubah luaran

$$
y^{1}=\frac{1}{m a}\left(\frac{p_{\eta} \cos \eta}{\sqrt{\sinh ^{2} \xi+\sin ^{2} \eta}}+\frac{p_{\mu}}{\cosh \xi \cos \eta}\right)
$$

\section{PENUTUP}


Sistem mekanik dengan kendala tak holonomik untuk Stroller yang bergerak di bidang datar dan di permukaan dalam bola pepat dapat digambarkan dengan metode Port Controlled Hamiltonian System (PCHS), yaitu sistem dinamika yang dapat digambarkan dengan himpunan persamaan diferensial dan energi sistem akan dinyatakan dengan tegas. Hasil penelitian ini sebagai landasan untuk berpijak dalam meneliti sistem mekanik dengan kendala holonomik pada stroller yang bergerak pada bidang lengkung lainnya dengan energi yang tidak dibatasi, dan persamaan PCHS pada stroller dapat digunakan untuk menemukan persamaan dinamika untuk penelitian tentang mekanika geometri lainnya.

\section{REFERENSI}

Akhsan, H., Wiyono, K., Ariska, M., \& Melvany, N. E. (2020). Development of HOTS (higher order thinking skills) test instruments for the concept of fluid and harmonic vibrations for high schools. Journal of Physics: Conference Series, 1480(1). https://doi.org/10.1088/17426596/1480/1/012071

Ariska, M., Akhsan, H., \& Muslim, M. (2020a). Dynamic Analysis of Tippe Top on Cylinder's Inner Surface with and Without Friction based on Routh Reduction. Journal of Physics: Conference Series, 1467(1). https://doi.org/10.1088/17426596/1467/1/012040

Ariska, M., Akhsan, H., \& Muslim, M. (2020b). Potential energy of mechanical system dynamics with nonholonomic constraints on the cylinder configuration space. Journal of Physics: Conference Series, 1480(1). https://doi.org/10.1088/17426596/1480/1/012075

Ariska, M., Akhsan, H., \& Muslim, M. (2019). Utilization of physics computation based on maple in determining the dynamics of tippe top. Journal of Physics: Conference Series, 1166(1). https://doi.org/10.1088/17426596/1166/1/012009

Ariska, Melly, Akhsan, H., \& Muslim, M. (2020a). DINAMIKA SISTEM MEKANIK NON-HOLONOMIK DENGAN METODE. 6(1), 20-23.

Ariska, Melly, Akhsan, H., \& Muslim, M. (2020b). Vector Fields of the Dynamics of Non-Holonomic Constraint System With Elliptical Configuration Space. 513, 738-744.

Ariska, Melly, Akhsan, H., \& Zulherman, Z. (2018). Utilization of Maple-based Physics Computation in Determining the Dynamics of Tippe Top. Jurnal Penelitian Fisika Dan Aplikasinya (JPFA), 8(2), 123. https://doi.org/10.26740/jpfa.v8n2.p123131

Blankenstein, G. (2003). Symmetries and locomotion of a $2 D$ mechanical network: the Snakeboard. July, 1-16.

Bou-Rabee, N. M., Marsden, J. E., \& Romero, L. A. (2004). Tippe top inversion as a dissipation-induced instability. SIAM Journal on Applied Dynamical Systems, 3(3), 352-377. https://doi.org/10.1137/030601351

Bou-Rabee, N. M., Marsden, J. E., \& Romero, L. A. (2008). Dissipation-induced heteroclinic orbits in tippe tops. SIAM Review, 50(2), 325-344. https://doi.org/10.1137/080716177

Branicki, M., Moffatt, H. K., \& Shimomura, Y. (2006). Dynamics of an axisymmetric body spinning on a horizontal surface. III. Geometry of steady state structures for convex bodies. Proceedings of the Royal Society A: Mathematical, Physical and Engineering Sciences, 462(2066), 371390.

https://doi.org/10.1098/rspa.2005.1586

Branicki, M., \& Shimomura, Y. (2006). Dynamics of an axisymmetric body spinning on a horizontal surface. IV. Stability of steady spin states and the "rising egg" phenomenon for convex axisymmetric bodies. Proceedings of the Royal Society A: Mathematical, Physical and Engineering Sciences, 462(2075), 3253-3275.

https://doi.org/10.1098/rspa.2006.1727

Ciocci, M. C., \& Langerock, B. (2007). Dynamics of the tippe top via Routhian reduction. Regular and Chaotic Dynamics, 12(6), 602-614. https://doi.org/10.1134/S1560354707060 032

Ciocci, M. C., Malengier, B., Langerock, B., \& Grimonprez, B. (2012). Towards a prototype of a spherical tippe top. Journal of Applied Mathematics, 2012. https://doi.org/10.1155/2012/268537

Fowles, G. R., \& Cassiday, G. L. (2004). Analytical Mechanics (7th Edition).

Glad, S. T., Petersson, D., \& RauchWojciechowski, S. (2007). Phase space of rolling solutions of the tippe top. Symmetry, Integrability and Geometry: 
Methods and Applications (SIGMA), 3. https://doi.org/10.3842/SIGMA.2007.041

Gray, C. G., \& Nickel, B. G. (2000). Constants of the motion for nonslipping tippe tops and other tops with round pegs. American Journal of Physics, 68(9), 821828. https://doi.org/10.1119/1.1302299

Naomi Altman \& Martin Krzywinski. (2015). Simple linear regression. BMJ (Online), 346(7904), 999-1000. https://doi.org/10.1136/bmj.f2340

Rauch-Wojciechowski, S., Sköldstam, M., \& Glad, T. (2005). Mathematical analysis of the tippe top. Regular and Chaotic Dynamics, 10(4), 333-362. https://doi.org/10.1070/RD2005v010n04 ABEH000319

Rutstam, N. (2010). Study of equations for tippe top and related rigid bodies (Doctoral dissertation, Linköping University Electronic Press). http://liu.divaportal.org/smash/get/diva2:359340/FULL TEXT01

Shaidullin, R. N., Safiullin, L. N., Gafurov, I. R., \& Safiullin, N. Z. (2014). Blended Learning: Leading Modern Educational Technologies. Procedia - Social and Behavioral Sciences, 131(904), 105-110. https://doi.org/10.1016/j.sbspro.2014.04. 087

Ueda, T., Sasaki, K., \& Watanabe, S. (2005). Motion of the tippe top: Gyroscopic balance condition and stability. SIAM Journal on Applied Dynamical Systems, 4(4), 1159-1194. https://doi.org/10.1137/040615985

Zobova, A. A. (2012). Comments on the Paper by M.C. Ciocci, B. Malengier, B. Langerock, and B. Grimonprez "Towards a Prototype of a Spherical Tippe Top." Regular and Chaotic Dynamics, 17(3-4), 367-369.

https://doi.org/10.1134/S1560354712030 112 